\title{
PRIMERAS TRADUCCIONES HISPÁNICAS DEL TRATADO DE AMICITIA DE CICERÓN
}

\author{
Carlos Hernández-Comendador Corral \\ carloslamuedra@hotmail.com
}

\section{RESUMEN}

El propósito de este artículo es establecer cronológicamente la recepción, presencia y difusión de Cicerón en la Península Ibérica a través de las traducciones del diálogo De Amicitia hasta 1600. En él daremos cuenta de cada uno de los traductores que se encargaron de esta tarea y asimismo incluiremos cuantos datos biográficos y bibliográficos hemos encontrado. Finalmente proponemos el cotejo y comparación de fragmentos escogidos de las distintas traducciones, no sólo entre ellas, sino con respecto a un incunable latino y a una edición moderna.

PalabRas Clave: Traducción. Tradición Clásica. Latín. Lengua Española. Renacimiento.

\section{Abstract}

The aim of this article is to clarify the reception, presence and spreading of Cicero all over the Iberian Paeninsula, and more particularly to provide a deeper insight of the peninsular translations of the «De Amicitia» dialogue up to 1600 A.D. With this purpose in mind, we will list out every single translator that devoted himself to this task; and we will also include as many biographical data as we have came across. Last, but not least, we offer the collating and comparison of selected extracts from several translations, not only between them, but also regard to the original Latin version.

KeY wORDS: Translation. Classical Tradition. Latin language. Spanish language. Renaissance. 
Poco exhaustivo es el catálogo de la producción de Cicerón a lo largo de la edad media según doña Margarita Morrás Ruiz Falcó ${ }^{1}$. Dado que no existió compendio alguno de sus obras, y menos aún de las llamadas obras morales, todo lo que podemos tener no son sino datos aproximados. Según dicha estudiosa, este diálogo moral gozó de poca difusión en comparación con las otras obras morales de Cicerón y sobre todo con el resto de su producción especialmente retórica ${ }^{2}$.

El primer testimonio de una traducción a una lengua romance de este diálogo es el de la traducción al francés del De amicitia, el De l'amitié hecho por Laurent de Permafreit, terminado en 1416 a instancias de Jean de Barry ${ }^{3}$. Por otra parte aporta el dato de una traducción al inglés hecha por Tiptoft.

Por lo que respecta al ámbito ibérico, se hubo de esperar hasta el siglo XI para tener noticias del original latino De amicitia, más concretamente en el monasterio de Ripoll ${ }^{4}$, texto que no ha llegado hasta nosotros.

Parece ser que la situación en Castilla con respecto al comercio de libros con Italia únicamente ha dejado «un puñado de obras» ${ }^{5}$ de modo que sólo se nos ofrece un «arriesgado ejercicio de imaginación» al intentar entrever el panorama de las obras en latín de Cicerón que pudieron haber circulado. Habría que recurrir al escrutinio de las principales bibliotecas particulares para tratar de establecer si en sus catálogos recogen alguna referencia a nuestro diálogo.

Según las noticias de que disponemos, la biblioteca de don Pedro Fernández de Velasco, Conde de Haro, albergó un De amicitia que ha llegado a nuestros días ${ }^{6}$. Del mismo modo el Marqués de Priego poseyó otro ejemplar?

Sabemos que «De mediados del siglo Xv son las traducciones de De la Amistad que poseía el Marqués de Santillana y el De la vejez que realizó Alfonso de Cartagena» ${ }^{8}$. Habiendo revisado la biblioteca9 ${ }^{9}$ del primero, hemos encontrado que ninguna de estas traducciones están vertidas al español, véanse a continuación qué obras de Cicerón poseía don Íñigo López de Mendoza.

De tan amplio catálogo parece necesario, además de conveniente, distinguir las obras originales en latín por una parte y por otra, las traducciones a cualquiera de las lenguas vernáculas no sólo peninsulares. En efecto, el Marqués poseía solamente en

\footnotetext{
${ }^{1}$ Morrás Ruiz Falcó, María(1993): Alonso de Cartagena: edición y estudio de sus traducciones de Cicerón, Barcelona, Bellaterra, Universitat Autònoma de Barcelona, p. 148.

${ }^{2}$ Este artículo ha tenido su génesis en el más amplio trabajo dirigido por la Dra. D ${ }^{a}$ Doña Carmen Teresa Pabón de Acuña, enmarcado en el Proyecto de Investigación: Estudio filológico de los textos clásicos latinos transmitidos en impresos incunables y postincunables conservados en España FFI2011-23685, y que constituyó el Trabajo de Investigación para la obtención del Diploma de Estudios Avanzados en el Departamento de Filología Clásica de la U.N.E.D, y cuyo título es «Primeras traducciones al español del diálogo De amicitia de Cicerón».

${ }^{3}$ Op.cit. 172.

4 Op.cit. 176-7.

5 Op.cit. 182.

${ }^{6}$ Op.cit.185. Biblioteca Nacional de Madrid. MSS/12839, MSS/9502, MSS/9225.

7 Op.cit. 188.

${ }^{8}$ GILBERT, Highet (1954): La tradición clásica: influencias griegas y romanas en la literatura occidental, México, D.F, Fondo de Cultura Económica, p.191.

${ }^{9}$ SCHIF, Mario (1970): La bibliothéque du Marquis de Santillane: étude historique et bibliographique de la collection de livres manuscrits de don Iñigo López de Mendoza, 1398-1458, Amsterdam, Gérard Th. van Heusden.
} 
latín las siguientes obras, un De oratore ${ }^{10}$, mientras que el resto son traducciones. Así un manuscrito ${ }^{11}$ que contenía el De officciis, De Amicitia, De paradoxis, De Senectute, traducido al italiano, otro manuscrito que albergaba las Tusculanas ${ }^{12}$, también en italiano, otro manuscrito ${ }^{13}$ traducido al aragonés que contenía De officiis y De Amicitia. Parece ser que también poseyó un De Senectute ${ }^{14}$ en italiano ${ }^{15}$.

Queda demostrada la importancia de la traducción de otras lenguas vernáculas como vehículo de transmisión de ideas y modas, además de la importante y frecuente relación interlingüística de la Romania. Igualmente es de destacar el interés que suscitaron los escritos llamados morales de Cicerón.

El hecho de que en la biblioteca personal del Marqués de Santillana no se haya encontrado ningún texto de Cicerón traducido al español, no empece la difusión de su obra. Como afirma Carlos Alvar ${ }^{16}$, a lo largo de la Edad Media fueron mucho más frecuentes las traducciones a nuestra lengua que emplearon alguna versión intermedia, que las directas. Además, la larga lista de incunables disponibles así lo corrobora. Mencionamos a continuación cuantos ejemplares se conocen y en primer lugar el texto que aportamos como término de la comparación posterior. Se trata del texto impreso en Milán por Guillermus Le Signerre entre 1498-1499 ${ }^{17}$. Otras muchas son las ediciones que incluyen este diálogo, como las de Leipzig del Laelius sive de amicitia de los años 1499, 1506, 1507 y 1518.

En cuanto a los traductores y las obras traducidas, Alfonso de Cartagena tradujo ${ }^{18}$ dos obras de Cicerón, De Senectute y De Officiis ${ }^{19}$ entre 1421 y 1422, a petición de Juan Alfonso de Zamora, pero no tradujo De amicitia. Esta ausencia es la que nos hace indagar más para intentar dilucidar quién y cuándo lo hizo por vez primera a nuestra lengua española. Además, el obispo de Burgos tradujo el discurso Pro Marcello aproximadamente entre 1422 y 1427 y una obra de retórica, la Rethórica de M. Tulio, más concretamente el De inventione, hacia 1430, dedicada a don Duarte de Portugal de la que sólo se ha conservado el libro I.

En este mismo siglo Xv sólo otro traductor se dedicó a Cicerón. Este fue Gonzalo de la Cavallería quien, según don Marcelino Meléndez Pelayo ${ }^{20}$, parece haber sido el autor de la traducción al aragonés que arriba citamos como perteneciente a la biblioteca del Marqués de Santillana.

${ }^{10}$ Op.cit. 58. Biblioteca Nacional de Madrid. MSS/10218

11 Op.cit. 59. Biblioteca Nacional de Madrid. MSS/9502

12 Op.cit. 60. Tusculanes. Biblioteca Nacional de París.

13 Op.cit. 63.Biblioteca Nacional de Madrid. MSS/10246

14 Op.cit. 64. MSS/10218

15 Estamos trabajando en la localización de estos ejemplares con la intención de ofrecer una descripción de los mismos.

${ }^{16}$ Alvar, Carlos (2010): Traducciones y traductores: materiales para una historia de la traducción en Castilla durante la Edad Media, Alcalá de Henares, Centro de Estudios Cervantinos, p. 245.

17 Cicero, Marcus Tullius, Opera, Milán, 1498-99. BN (Inc./1831-2) .

18 Alvar, Carlos (2009): Repertorio de traductores del siglo XV, Madrid, Ollero y Ramos, p. 57.

${ }_{19}$ Morrás, María (1966): Marco Tulio Cicerón, Libros de Tulio: De senetute. De los ofiçios, Alcalá de Henares, Universidad de Alcalá de Henares.

${ }^{20}$ Menéndez y Pelayo, Marcelino (1952): Biblioteca de traductores españoles, Madrid, CSIC, vol I. p.263. 
Esto es lo que hemos encontrado sobre Cicerón y sus traducciones en el panorama peninsular del siglo XV. Se ha de hacer mención, asimismo, del traductor luso Vasco Fernández de Lucena ${ }^{21}$ quien tradujo el De senetute, De velhice.

Resulta significativo, que en el amplio panorama traductográfico del siglo Xv, este diálogo de Cicerón no fuera traducido. Que un diálogo tan importante fuera dejado al margen durante tanto tiempo sólo puede explicarse por tres motivos. O que no hubiera llegado noticia de él ni manuscrito alguno en que fijarse para su traducción, o que se soslayase por alguna tendencia ética o política, o que de hecha se haya perdido. Habría de acometerse un estudio en profundidad sobre este punto, para intentar arrojar cierta luz sin recurrir a juicios prematuros, pero no es esta la intención de este trabajo, aunque tal vez lo emprendamos más adelante.

Se habría de esperar hasta entrado el siglo XVI para encontrar otros traductores. Tres fueron quienes se dedicaron a la traducción de Cicerón y más concretamente al diálogo que nos ocupa.

\section{Fray Ángel CORNEJo}

El primero de ellos es Fray Ángel Cornejo de quien hasta la fecha no hemos encontrado ningún dato de su biografía. Poco es lo que se conoce de él, salvo que fue cisterciense y tradujo el De Amicitia. Noticia de él nos da don Marcelino Menéndez Pelayo ${ }^{22}$ quien afirma que tradujo el Lelio de Cicerón junto con el Toxaris de Luciano y que se le dio el nombre de Libro llamado Arte de Amistad. Difícil es ofrecer una fecha, ni siquiera aproximada, para esta traducción por cuanto la única referencia de que se puede disponer es la del impresor que la dio a la luz en Medina del Campo en 1548 pero no se sabe cuánto tiempo yació en el abandono en las prensas medinenses ${ }^{23}$. También da testimonio del mismo libro don Pedro Cátedra ${ }^{24}$.

\section{CRistóbal de CASTillejo}

De mediados del siglo XVI es la traducción de Cristóbal de Castillejo ${ }^{25}$. Difícil ha sido dar con él en su oficio de traductor porque ni siquiera Menéndez Pelayo ${ }^{26}$ da cuenta en su Biblioteca de Traductores de estos dos tratados -quizá por no encontrarse el ma-

${ }^{21}$ RusselL, P.E (1985): Traducciones y traductores en la península Ibérica: (1400-1550), Barcelona, Bellaterra, p.38.

${ }^{22}$ Op.cit. I, p.380.

${ }^{23}$ Menéndez y Pelayo, Marcelino (1950): Bibliografía Hispano-Latina Clásica, Santander, p.331. Recoge la siguiente afirmación sobre el editor de la obra del fraile:

«Entre otros muchos originales escriptos de mano tenía yo una obrecica de Tulio, cuyo título es de Amicitia, traducida en nuestro vulgar castellano, con otro diálogo de Luciano, por un reverendo y docto monje, y á v. m. dirigida, y visto que se había ya pasado mucho tiempo, que no había memoria della, determiné sacarla á luz.» (BN R/27041)

${ }_{24}$ Pérez Pastor, Cristóbal (1992): La imprenta en Medina del Campo, Valladolid, Junta de Castilla y León, Consejería de Cultura y Turismo, p. 51.

${ }^{25}$ Beccaría Lago, María Dolores (1977): Vida y obra de Cristóbal de Castillejo, Madrid, Real Academia Española y Reyes Cano, Rogelio(1999): Obra completa de Cristóbal de Castillejo, Madrid, Fundación José Antonio de Castro.

${ }^{26}$ Op.cit. 
nuscrito en España, como afirman Reyes Cano $^{27}$ y Beccaría ${ }^{28}$ - aunque ambos diálogos ciceronianos, De amiticia y De senectute, fueron traducidos por el mirobrigense.

No es nuestro propósito hablar en extenso de la vida y obra de don Cristóbal, otros lugares hay en que suplir tal falta; sí mencionaremos los más importantes. Empero, tenemos más que abundantes en comparación con Tamara, cuyos datos biográficos son apenas nulos, o de Cornejo, que lo son igualmente y sin atenuantes. Nacido en 1490 en Ciudad Rodrigo, provincia de Salamanca, y fallecido en Viena en 1550, se le conoce fundamentalmente por su oficio de poeta. Aparte de su producción poética, que le dio la fama, hemos de centrarnos en su otra labor -casi desconocida-. Como humanista, se ocupó de los clásicos y tradujo fragmentos de Ovidio (Polifemo, Acteón, Píramo y Tisbe) y los tratados de Cicerón De Senectute y De amicitia ${ }^{29}$. Fueron estos dos los únicos textos traducidos que se llegaron a imprimir, junto con la «Carta dedicatoria», en que el mirobrigense reflexiona sobre su oficio de traductor.

Es difícil dar una fecha cierta para casi todas las obras de Castillejo, si bien quizá estas dos traducciones, por el propio asunto que tratan, la vejez y la amistad, pudieran pertenecer a los años finales de su vida, ya asentado en Viena.

\section{Francisco TAMARA}

El tercer traductor que acometió la tarea de verter estas dos obras morales del arpinate fue Francisco Tamara ${ }^{30}$. Le encontramos traduciendo también De officiis, como si de la mano de Alfonso de Cartagena fuera guiado.

Largamente olvidado $^{31}$, no fue hasta principios del pasado siglo cuando Adolfo Bonilla y San Martín ${ }^{32}$ le rescató, para centrarse en su traducción de «Los apotegmas» de Erasmo. Casi medio siglo después, Marcel Bataillon ${ }^{33}$ vuelve a ponerle sobre la mesa también a propósito de su traducción de Erasmo.

Poco es lo que se sabe de su vida. No hay ningún dato certero de su nacimiento debido a la falta de documentos anteriores a 1596, fecha del saqueo inglés de Cádiz. Según Rabaey $^{34}$ en 1543 ya vivía en la ciudad y en 1556 seguía viviendo en ella. Entre 1546 y ésta última fecha Tamara, publicó cinco traducciones y una obra de su propia autoría.

Aparte de presentárnoslo como traductor esporádico de Ennio, Pacuvio y Estacio, don Marcelino Menéndez Pelayo, en su obra sobre los traductores españoles ${ }^{35}$, recoge como primera obra impresa en Sevilla en 1545, el volumen en que se inserta la traduc-

${ }^{27}$ Op.cit. xxiv. El único que consta está en Viena. Ms. 12817 (Codex Vindobonenis Palatinus) ÖNW fols. $34 \mathrm{v}-68 \mathrm{v}$

28 Op.cit.367.

${ }^{29}$ Ruiz Casanova, José Francisco(2000): Aproximación a una historia de la traducción en España, Lingüística, Madrid, Cátedra, p. 163-7.

${ }^{30}$ Encontramos su apellido escrito de diferentes formas: Támara, Tamara, Thamara, Tamara.

31 Rabaey, Hélène (2002): «Francisco de Támara: Algunos apuntes biográficos», Calamus Renascens III, pp.549-54.

32 Bonilla y Sanmartín, Adolfo (1907): «Erasmo en España», Revue Hispanique, XVII, pp. 379-548.

33 Bataillon, Marcel (1986): Erasmo y España: estudios sobre la historia espiritual del siglo XVI, México. D.F, Fondo de Cultura Económica, p. 628.

${ }^{34}$ Op.cit. pp. 549-54.

35 Op. cit. Vol IV, p. 275. 
ción de los tres libros de Cicerón De los oficios, De la amistad, y De la senectud. Se añaden para completar el libro impreso, una traducción del Económico de Jenofonte, también de Tamara, y las traducciones de Juan de Jarava de las Paradojas de Cicerón y del Sueño de Escipión. Este volumen gozó de mucha fortuna como se puede deducir por sus reimpresiones. También así los Apotegmas de Erasmo publicado en Amberes en 1549.

En 1550 el libro de Polidoro Virgilio De inventoribus que tituló Libro de Polidoro Virgilio que tracta de la invención y principio de todas las cosas. Esta traducción fue publicada en Amberes en 1550 y fue dedicado a don Luis Cristóbal Ponce de León, duque de Arcos. Poco después debió de publicarse la Suma y compendio de todas las chrónicas del mundo desde su principio hasta el año presente, traducción del Chronicon de Juan de Carrión, impresa en Amberes y en Medina del Campo en 1553.

En 1556 llevó a cabo la traducción del Omnium gentium mores Libro de las costumbres de todas las gentes del mundo de Juan Boemus fechado en 1520, fue impreso también en Amberes y lo dedicó a Juan Carlos de Guzmán, Conde de Niebla.

Parece ser que entre 1543 y 1556 Tamara siguió viviendo y traduciendo en la comarca de Cádiz por lo que se deduce de los destinatarios de sus traducciones, todos nobles gaditanos o fronterizos.

Que fue traductor de los autores clásicos en su estancia en la ciudad de Cádiz, lo sabemos de primera mano por la noticia que da Nicolás Antonio:

Franciscus Tamara interpretem egit veterum auctorum cum esset in Gaditana urbe humaniorum studiorum profesor, scripsit nempe seu vertit in vulgarem sermonem ${ }^{36}$.

Poco más es lo que se puede colegir de tan vagos datos. Don Luis Charlo Brea ${ }^{37}$ cita una fuente que a su vez recoge la noticia que hace a Tamara gaditano de cuna, pero sin mayor certeza y catedrático de Latín en Cádiz en la primera mitad del siglo XVI. Afirma que murió en 1561.

Además de su oficio de traductor, don Francisco Tamara escribió dos obras originales: Suma y erudición de Gramática editada en Amberes en casa de Martín Nucio en 1550 y los Grammatica rudimenta que vio la luz en 1892 en la imprenta de Ricardo Fé por encargo del Conde de la Viñaza.

\section{FRAGMENTOS ESCOGIDOS}

Cotejamos ahora las tres traducciones con un incunable ${ }^{38}$ latino. Para llegar a un juicio analítico comenzaremos por el principio, antepondremos la versión latina tomada de la edición del incunable, seguida de las traducciones de Tamara, Castillejo y Cornejo respectivamente y en este orden.

\footnotetext{
36 Antonio, Nicolás (1999): Biblioteca Hispana Nueva, o de los escritores españoles que brillaron desde el año MD hasta el de MDCLXXXIV, Madrid, Fundación Universitaria Española, p.483.

${ }^{37}$ Para mayor profundidad en fuentes documentales que aclaren algo la vida de nuestro autor véase el artículo entero. Charlo Brea, Luis (2001): «La Grammatices rudimenta de Franciso de Thámara, Calamus Renascens», Calamus Renascens, II, pp. 77-105.

${ }^{38}$ Cicero, Marcus Tullius, Opera, Milán, 1498-99
} 


\begin{tabular}{|c|c|c|c|}
\hline Incunable & Tamara & Castillejo & Cornejo \\
\hline $\begin{array}{l}\text { I.1 Vintus Mucius augur } \\
\text { Scevola multa narrare } \\
\text { de C. Laelio socero suo } \\
\text { memoriter \& iucunde } \\
\text { solebat nec dubitare illum } \\
\text { in omni sermone appellare } \\
\text { sapientem. }\end{array}$ & $\begin{array}{l}\text { Quinto Mucio } \\
\text { Scevola, aquel que } \\
\text { fue del colegio } \\
\text { de los Augures, } \\
\text { muchas cosas solia } \\
\text { contar y platicar } \\
\text { agradablemente, de } \\
\text { cayo Lelio su suegro: } \\
\text { y no dudava en todas } \\
\text { sus razones darle } \\
\text { nombre de sabio. }\end{array}$ & $\begin{array}{l}\text { Solía Quinto Mucio } \\
\text { Scévola, el augur, } \\
\text { contar alegremente } \\
\text { muchas cosas de su } \\
\text { suegro Cayo Lelio, el } \\
\text { qual no dubdava en } \\
\text { todas sus ablas llamar } \\
\text { savio. }\end{array}$ & $\begin{array}{l}\text { Quinto Mucio Scevola } \\
\text { sacerdote muchas cosas } \\
\text { de Cayo Lelio suegro } \\
\text { suyo acostumbrava } \\
\text { contar dignas por cierto } \\
\text { de perpetuo nombre, de } \\
\text { adonde no dudava jamas } \\
\text { llamarle sabio. }\end{array}$ \\
\hline
\end{tabular}

Es evidente que el traductor respeta el sentido general, pero amplía el texto con datos que no hay en el original y que tal vez considere oportunos para mejor conocimiento de sus lectores. No se debe olvidar que el texto va flanqueado por notas marginales -que incluso pudieran no ser suyas- que persiguen el mismo fin, lo cual no hace sino demostrar que se trata de un punto que requería cierto comentario o explicación.

Así, Tamara expande la función de aposición que en latín tiene la palabra augur con una oración de relativo. Al agregar «el colegio de los Augures» cabe pensar que pretende destacar la importancia de los augures -que Cicerón sin duda tenía en mente- aunque no lo señalaba tanto como el propio traductor. En este punto el incunable ofrece una ausencia de la letra capital «Q» así Vintus Mutius Augur Scevola.

En cambio, de los adverbios memoriter y iucunde, que modifican el núcleo de la estructura del infinitivo concertado narrare, sólo traduce el segundo omitiendo el primero, en lo que coincide con Castillejo; a este propósito es notable la diferencia de los matices de los adverbios que emplean uno y otro para trasladar el iucunde: «agradablemente», «alegremente»; Cornejo, por su parte, prescinde del primero y recoge el segundo con una perífrasis: «dignas por cierto de perpetuo nombre». Respecto a narrare, Tamara lo amplía a «contar y platicar», con lo que de nuevo, aún a riesgo de parecer subjetivos, da la impresión de querer saborear y ampliar la conversación familiar. En cambio los otros dos traductores sólo reflejan narrare por un único «contar».

\begin{tabular}{|c|c|c|c|}
\hline Incunable & Tamara & Cornejo & Castillejo \\
\hline $\begin{array}{l}\text {...ego autem a patre } \\
\text { ita eram deductus ad } \\
\text { Scaevolam sumpta virili } \\
\text { toga ut quoad possem } \\
\text { et liceret a senis latere } \\
\text { numquam discederem }\end{array}$ & $\begin{array}{l}\text { En este tiempo, aviendo } \\
\text { yo tomado la vestidura } \\
\text { de la toga, ya entraba en } \\
\text { los años de discrecion, } \\
\text { muchas vezes me solia } \\
\text { mi padre llevar a casa } \\
\text { de Scevola, para que } \\
\text { todo el tiempo que } \\
\text { yo pudiesse, y me } \\
\text { fuesse licito, nunca } \\
\text { me apartasse de la } \\
\text { compañia y lado de } \\
\text { aquel viejo. }\end{array}$ & $\begin{array}{l}\text { Y yo, después que tomé } \\
\text { la vestidura de honbre, } \\
\text { fui llevado a él por mi } \\
\text { padre con intención } \\
\text { y mandado que, en } \\
\text { quanto pudiese y me } \\
\text { fuesse lícito, nunca del } \\
\text { lado de aquel viejo me } \\
\text { apartasse. }\end{array}$ & $\begin{array}{l}\text { Yo despues de tomada } \\
\text { la toga viril con tanto } \\
\text { cuydado segui a Scevola } \\
\text { ( por quanto avia sido } \\
\text { encomendado a el de } \\
\text { mi padre) que jamas } \\
\text { podiendo en los tiempos } \\
\text { que convenia de su lado } \\
\text { me apartava }\end{array}$ \\
\hline
\end{tabular}


Tamara añade una circunstancia temporal que no se encuentra en el original, pero no traduce el autem. Un notable y curioso incremento de la materia léxica advertimos en el traslado del mínimo sintagma nominal en ablativo absoluto, sumpta virili toga, que se expande en una oración de gerundio compuesto a la que añade un juicio de valor, -en cierta medida explicativo- como si de una nota al pie se tratara como aclaración, pero inserta en el propio cuerpo de la traducción, «ya entraba en los años de discreción», con ello refleja a su modo el adjetivo virili. Además establece una frecuencia iterativa en el hecho puntual a patre ita eram deductus, «muchas vezes me solía mi padre llevar». Sin duda refuerza la idea que viene después del quoad possem et liceret. Incrementa también el circunstancial de dirección ad Scaevolam, junto a Escévola, concretando el espacio de la acción en su casa, en un castizo «a casa de Escévola».

Respeta totalmente la estructura y el sentido de la temporal dentro de la adverbial subordinada final o consecutiva, quoad possem et liceret, «todo el tiempo que pudiesse y me fuesse licito», y sobre todo, la doble modalidad deóntica explicitada por la posibilidad y la licitud; a senis latere numquam discederem, «nunca me apartasse de la compañía y lado de aquel viejo». Incrementa, en cambio, y redunda la noción de compañía, no presente en el original.

Mucho más ceñida al original es la versión de Castillejo, que -al menos en las primeras palabras- respeta la traducción de ego autem, «y yo», el toga virili lo traslada como «la vestidura de honbre» y la voz del verbo, «fui llevado por mi padre», queda también en pasiva, pero omite, en cambio, el nombre del augur. Empero, como si quisiera compensar lo anterior, el ut lo traduce por: «con intención y mandado».

Basta con leer la traducción de Cornejo para apreciar la diferencia que existe entre la suya y las otras dos traducciones. El sintagma toga virili está vertido como esperaríamos frente a los dos casos vistos. El resto, en cambio, queda amplificado, en especial en los puntos que dice: «con tanto cuydado segui a Scevola», así como «por quanto avia sido encomendado a el de mi padre». Da la impresión de que, si en un caso anterior señalábamos la opinión de que Tamara recalcaba la figura de Escévola como augur, aquí Cornejo insiste en la actitud de Cicerón, como si estuviera cumpliendo el deseo de su padre que no sólo le llevó -como entienden los otros dos- sino que le encomendó.

\begin{tabular}{|c|c|c|c|}
\hline Incunable & Tamara & Castillejo & Cornejo \\
\hline $\begin{array}{l}\text { itaque multa ab eo } \\
\text { prudenter disputata, } \\
\text { multa \& breviter } \\
\text { \& commode dicta } \\
\text { memoriae mandabam } \\
\text { fierique studebam eius } \\
\text { prudentia doctior. }\end{array}$ & $\begin{array}{l}\text { Y yo también procurava } \\
\text { de encomendar a mi } \\
\text { memoria muchas } \\
\text { cosas muy breves y } \\
\text { provechosas, que el } \\
\text { prudentemente disputava } \\
\text { y dezia, y trabajava de } \\
\text { ser siempre mas docto } \\
\text { por su prudencia. }\end{array}$ & $\begin{array}{l}\text { De manera que notava } \\
\text { y encomendava a } \\
\text { la memoria muchas } \\
\text { cosas disputadas por } \\
\text { él prudentemente y } \\
\text { otras muchas dichas a } \\
\text { propósito y de presto, y } \\
\text { procurava de aprender y } \\
\text { hazerme más docto con } \\
\text { su prudencia. }\end{array}$ & $\begin{array}{l}\text { Assi que cosas muchas } \\
\text { del disputadas con gran } \\
\text { prudencia y muchas } \\
\text { cosas dichas con gran } \\
\text { discrección y saber } \\
\text { procurava yo con gran } \\
\text { diligencia encomendallas } \\
\text { a la memoria desseando } \\
\text { alcançar alguna erudicion } \\
\text { et la mucha que del a } \\
\text { cada palabra salia. }\end{array}$ \\
\hline
\end{tabular}


Tamara cambia el orden del párrafo, de modo que amplifica la estructura con la inclusión de una oración relativa, que parece querer ser la forma analítica de un simple y conciso participio de perfecto pasivo en acusativo, objeto de mandabam. Quizá sea fruto de su afán por destacar la labor de Escévola que revertiría en el propio Cicerón. Más abajo recoge el participio de perfecto pasivo: ab eo disputata dicta, y lo cambia de categoría, vertiéndolo en forma personal activa, para lo cual, -como es natural- trasforma el complemento agente de los participios pasivos a sujeto de los verbos conjugados «disputava y dezía». En cuanto a los adverbios, breviter, commode, se ha inclinado por traducirlos como adjetivos. Debía de ser una preferencia estética.

Castillejo, por su parte, mantiene el participio latino, pero desdobla el verbo mandabam por «notava y encomendava» que se refiere a la actitud de Cicerón, y después sigue con este procedimiento con los dobletes: «a propósito y de presto», «aprender y hazerme más docto».

Cornejo es el que se atiene más al texto en la primera parte; desde el fierique se deja llevar por cierto apasionamiento justo hasta el punto en que no quiebre la unidad semántica con el texto latino.

\begin{tabular}{|c|c|c|c|}
\hline Incunable & Tamara & Castillejo & Cornejo \\
\hline $\begin{array}{l}\text { Quo mortuo me ad } \\
\text { pontificem Scaevolam } \\
\text { contuli quem unum } \\
\text { nostrae civitatis \& } \\
\text { ingenio \& iustitia } \\
\text { praestantissimum audeo } \\
\text { dicere. Sed de hoc alias } \\
\text { nunc redeo ad augurem. }\end{array}$ & $\begin{array}{l}\text { Muerto este Scevola, yo } \\
\text { me passe a la compañia } \\
\text { del otro Scevola } \\
\text { pontifice, del qual } \\
\text { osare dezir que fue un } \\
\text { varon el mas excelente } \\
\text { de nuestra ciudad, en } \\
\text { ingenio y industria: Pero } \\
\text { deste hablaremos en } \\
\text { otra parte. Buelvo agora } \\
\text { al primer Scevola el } \\
\text { Augur: }\end{array}$ & $\begin{array}{l}\text { Y después de su muerte, } \\
\text { dime y elleguéme al } \\
\text { pontífice Scévola, el } \\
\text { qual sólo oso dezir aver } \\
\text { sido el más señalado y } \\
\text { excelente en ingenio y } \\
\text { justicia de toda nuestra } \\
\text { ciudad. Pero dexando } \\
\text { esto para otro lugar, } \\
\text { tornemos agora al augur. }\end{array}$ & $\begin{array}{l}\text { Despues de su muerte } \\
\text { allegome al pontifice } \\
\text { Scevola al que en } \\
\text { ingenio et industria } \\
\text { el mas excelente y } \\
\text { señalado de nuestra } \\
\text { ciudad sin ningun } \\
\text { temor oso dezir, mas } \\
\text { de aqueste en otra } \\
\text { parte como prese mas } \\
\text { largamente hablar } \\
\text { dexandole buelvome al } \\
\text { primero. }\end{array}$ \\
\hline
\end{tabular}

Tamara mantiene literalmente la estructura de ablativo absoluto, mientras que Castillejo y Cornejo lo traducen -algo más libremente- por oraciones temporales. A partir de ahí las tres versiones ofrecen caminos ligeramente divergentes. Por una parte Tamara explica que se traduce por futuro el audeo, probablemente indicando cierto respeto para con el lector, que no pone Cicerón por innecesario y que quita fuerza a la afirmación. Especialmente interesante es el hecho de que escribe iustitia por «industria», como también hace Cornejo, lo que nos ha llevado a investigar en algunas ediciones antiguas y hemos comprobado que en los ejemplares de Leipzig de 1506 y de 1518 se encuentra dicha forma frente a otras contemporáneas editadas en la misma ciudad que traen el iustitia (1499, 1507). El incunable que nos sirve de base ofrece escrito en nota marginal en cursiva esta misma palabra, «industria». Hemos comprobado en la moderna edición de J.G.F Powell ${ }^{39}$ y no se recoge en el aparato crítico tal variante.

${ }^{39}$ Powell, J.G.F (2006): Marco Tulio Cicerón, M. Tulli Ciceronis De re publica ; De legibus ; Cato maior de senectute ; Laelius de amicitia, Oxford, Oxford Classical Texts. 
En las líneas siguientes volvemos a encontrar acompañando a Escévola el término «primero», que no trae el texto latino y que sin duda Tamara quiere aclarar.

Castillejo divide el contuli en dos formas, tal vez insiste en el interés de Cicerón y el superlativo praestantissimum, lo recoge con dos adjetivos «el más señalado y excelente».

La versión de Cornejo resulta a nuestro oído especialmente rebuscada por su acusado hipérbaton, pero no sabemos si al gusto de los lectores contemporáneos resultaba igual o no.

Finalmente, las últimas ocho palabras pueden ser uno de los ejemplos más claros de cómo el sintetismo de la oración latina no se puede verter al español. En amplificación gana aquí Cornejo aunque a diferencia de los otros, no pone «augur», sino «primero».

En líneas generales puede apreciarse el estilo bien marcado de cada traductor a la hora de ejercer su oficio. Todos ellos toman como base las teorías o doctrinas que sobre la traducción venían heredándose desde la Edad Media y las propias del Renacimiento.

Dentro de los pocos documentos teóricos sobre la traducción de que se pudieron servir nuestros traductores el más importante fue San Jerónimo. Expuso sus teorías sobre la traducción en su Epístola a Pamaquio escrita hacia 395 d.C como respuesta a unas críticas que le habían hecho de su trabajo como traductor del griego. En ella acuñó los conceptos que acompañarían a todos los traductores medievales:

En la intepretacion de los libros griegos non curo de exprimir una palabra por otra, mas sigo el seso et efecto, salvo las Sagradas Escripturas, porque allí la orden de las palabras trae misterio. $^{40}$

Afirma que no siempre una traducción fiel ha de ser verbum pro verbo excepto las de las sagradas escrituras. Es traductor quien logra extraer el sentido que subyace bajo esas palabras sensum exprimere de sensu. En este escrito se apuntalaron todos los tópicos venideros sobre la traducción.

Parece ser que todos los traductores medievales, y -podríamos decir que incluso del siglo XVI- según afirma Russell ${ }^{41}$, no sólo partieron de estos preceptos y estuvieron sujetos a ellos ${ }^{42}$ sino que no se desligaron de ellos.

\section{CONCLUSIONES}

Somos conscientes de que el ámbito de la traducción es uno de los más difíciles -si no el más- dentro del amplio campo de la Lingüística y si cabe, aún más en lo que respecta al de la Filología Clásica. Dada su naturaleza ancilar, siempre ha sido visto como una tarea secundaria y hasta prescindible. Pero igualmente no hay duda de que es de los más interesantes, sea para realizar la propia traducción, sea para analizar las ya hechas. Este último ha sido nuestro objetivo y debemos reconocer con humildad que se trata de un tema sobre el que no habíamos trabajado anteriormente y del que hemos visto nacer muchos aspectos que nos hubieran gustado analizar si hubieramos dispuesto del tiempo y la práctica necesarios.

\footnotetext{
${ }^{40}$ Tomo la traducción que hizo Alonso de Cartagena en MORREALE, M (1959): «Apuntes para la historia de la traducción en la Edad Media», Revista de Literatura XV, p.10.

41 Op.cit. p.43.

42 Op.cit. p.26.
} 
No obstante, esperamos que tal vez en el futuro se pueda abordar, al menos algunos de ellos, sobre todo en lo que respecta a la edición textual, o al estudio de la historia de la lengua española, o incluso más ampliamente a la difusión de estas ideas en el campo literario.

El estudio de las primeras traducciones que se hicieron en España del diálogo De Amicitia de Cicerón muestra que hay que llegar al siglo XVI para encontrarlas. A dicho aserto nos ha llevado el conjunto de materiales que hemos tenido a nuestro alcance y en los que hemos basado la presente investigación. Reconozco que sólo son datos actuales y no se puede afirmar que no vaya a aparecer ninguna otra versión de ese texto. Cada día, como es sabido, los medios informáticos y en general la investigación filológica aporta nuevos y asombrosos resultados. Quizá la explicación de esta ausencia tan marcada necesitara de un trabajo aparte, sobre todo centrado en textos incunables y en el intento de dar con el texto originario que pudieran haber manejado los traductores.

Dichas traducciones del siglo XVI corresponden a tres autores poco conocidos y menos estudiados. La carencia de noticias sobre sus vidas imposibilita llegar a conclusiones más completas que enriquecerían no sólo el ámbito que les rodea, sino incluso a la época en que vivieron.

La calidad de las traducciones se puede definir como aceptable en los tres casos, aunque si un estudioso lee esas tres versiones exclusivamente con un juicio actual tiene el riesgo de desenfocarlas y no valorarlas en su verdadera importancia.

Una característica general de ellas es la tendencia a la amplificación. Hay que distinguir la que hacen los traductores por mero gusto o preferencia, de las que llamaríamos explicativas («Scévola mi maestro», «aquel que fue del colegio de los augures», etc.). Éstas últimas deben relacionarse con el hecho de que probablemente los tres hicieran esas versiones con fines didácticos.

Aunque en un principio pensamos, y así lo hicimos constar, que era poco menos que imposible localizar los ejemplares que utilizaron estos traductores, el hecho de haber encontrado alguna variante textual nos ha dado cierto optimismo sobre la posibilidad de seguir en ese camino y hallar la versión de la que partieron o una que podría ser.

Como hemos podido apreciar a lo largo de la comparación, la más cercana al original e incluso la más amena para un lector actual es la de Castillejo, seguida de la de Tamara, sensiblemente más libre, y finalmente, la que ofrece Fray Ángel Cornejo, destaca por su tendencia al barroquismo, pero que en general mantiene el sentido del texto latino.

Quedamos emplazados para acometer ulteriores estudios que esclarezcan algunos aspectos, sobre todo textuales e incluso sobre las técnicas y los medios de que se pudieran haber servido nuestros traductores.

\section{BiBLIOGRAFÍA}

Alvar, Carlos (2009): Repertorio de traductores del siglo XV, Madrid, Ollero y Ramos.

- (2010): Traducciones y traductores: materiales para una historia de la traducción en Castilla durante la Edad Media, Alcalá de Henares, Centro de Estudios Cervantinos.

Antonio, Nicolás (1999): Biblioteca Hispana Nueva, o de los escritores españoles que brillaron desde el año MD hasta el de MDCLXXXIV, Madrid, Fundación Universitaria Española.

BataILlon, Marcel (1986): Erasmo y España: estudios sobre la historia espiritual del siglo XVI, México. D.F, Fondo de Cultura Económica. 
Beccaría Lago, María Dolores (1977): Vida y obra de Cristóbal de Castillejo, Madrid, Real Academia Española.

Bonilla y Sanmartín, Adolfo (1907): «Erasmo en España», Revue Hispanique.

Charlo Brea, Luis (2001): «La Grammatices rudimenta de Franciso de Thámara, Calamus Renascens», Calamus Renascens.

Cicero, Marcus Tullius, Opera, Milán, 1498-99

GILBERT, Highet (1954): La tradición clásica: influencias griegas y romanas en la literatura occidental, México, D.F, Fondo de Cultura Económica.

Menéndez y Pelayo, Marcelino (1950): Bibliografía Hispano-Latina Clásica, Santander.

- (1952), Biblioteca de traductores españoles, Madrid, CSIC.

Morrás Ruiz Falcó, María (1993): Alonso de Cartagena: edición y estudio de sus traducciones de Cicerón, Barcelona, Bellaterra, Universitat Autònoma de Barcelona.

- (1966): Marco Tulio Cicerón, Libros de Tulio: De senetute. De los ofiçios, Alcalá de Henares, Universidad de Alcalá de Henares.

Morreale, M (1959): «Apuntes para la historia de la traducción en la Edad Media», Revista de Literatura XV.

Pérez Pastor, Cristóbal (1992): La imprenta en Medina del Campo, Valladolid, Junta de Castilla y León, Consejería de Cultura y Turismo.

Powell, J.G.F (2006): Marco Tulio Cicerón, M. Tulli Ciceronis De re publica ; De legibus ; Cato maiorde senectute ; Laelius de amicitia, Oxford, Oxford Classical Texts.

RABAEy, Hélène (2002): «Francisco de Támara: Algunos apuntes biográficos», Calamus Renascens.

Reyes Cano, Rogelio (1999): Obra completa de Cristóbal de Castillejo, Madrid, Fundación José Antonio de Castro.

Ruiz Casanova, José Francisco (2000): Aproximación a una historia de la traducción en España, Lingüística, Madrid,Cátedra.

Russell, P.E (1985) Traducciones y traductores en la península Ibérica: (1400-1550), Barcelona, Bellaterra.

Schiff, Mario (1970), La bibliothéque du Marquis de Santillane: étude historique et bibliographique de la collection de livres manuscrits de don Iñigo López de Mendoza, 1398-1458, Amsterdam, Gérard Th. van Heusden. 